\title{
Teaching Reform of Web Project Development Courses based on CDIO Yong Sun ${ }^{1, a}$ \\ ${ }^{1}$ Department of Information Technology, Zhejiang Institute of Communications, Hang Zhou, 310012, China \\ aemail: sy@zjvtit.edu.cn
}

Keywords: CDIO; task-driven; teaching reform; process assessment

\begin{abstract}
In order to handle teaching problems of Web project development courses in higher education, we apply CDIO engineering education methods to the Web project development courses, focusing on enhancing the ability of engineering practice, reforming curriculum teaching content, teaching methods and assessment methods. Curriculum teaching content is around the Web project development process by the task-driven method. Many teaching methods are applied. Many assessment methods are used in the courses base on the combination of process assessment and objective assessment. It's proved by teaching practice that the reform of curriculum teaching greatly improved engineering practice, teamwork and innovation for students.
\end{abstract}

\section{Introduction}

Presently, in teaching of web project development students are lack of systematic training in engineering capabilities. In practice, students' interest and enthusiasm are not high enough. They learn passively. In the project practice they imitate the teachers' teaching case. Their software development capability, teamwork and communication skills can not be significantly improved. However, Web project development is a course closely integrated with the actual project development. It includes extensive knowledge of object-oriented programming, computer network, software engineering, database design, web design, CSS, XML data exchange technology and software system architecture. It is a course which requires higher comprehensive ability to the students. Through learning and practicing in the course, students can not only consolidate technical expertise, improve analytical skill and practical ability, but also develop good team spirit, adapt to the software project team in the demand for developing new systems and new products. Therefore, this course will be based on the actual needs of enterprises, adopt CDIO[1] engineering education methods, re-design the teaching content, reform the traditional teaching methods and assessment methods, explore a set of classroom teaching reform program for training excellent development engineer of web projects.

\section{The Reform of Curriculum}

According to the job requirements of web project development engineer, determine the course training objectives. Based on the actual needs of enterprises, applying CDIO engineering education methods, centering on the case, oriented to project tasks, the curriculum reform of classroom teaching are around the three aspects of curriculum teaching content, teaching methods and assessment methods.

Reform curriculum teaching content. Applying CDIO engineering teaching methods, combined with the training objectives of the course, research and design curriculum teaching content focusing on the D-I(design - achieve) of CDIO followed by C-O(Idea - run). Curriculum teaching content is centering on the entire case. According to web project development process, implement a complete software design process [2]. The project design and development tasks in the various stages include in-depth market research, need analysis, system design, system implementation, system testing, system deployment and acceptance. The process of project implementation will be issued in the form of task, and course tasks are interrelated. When students complete all tasks, they will have developed a complete project. After task is completed, students are required to hand over technical documentation and source code, and teachers inspect students' project. After all practice teaching contents are completed, the project teams must complete their project summary report, and 
project team members must write personal project summary report. By the end of the course, the project teams must demonstrate their web projects and participate in project oral defense.

Reform curriculum teaching methods. CDIO engineering education methods not only focus on training students' self-learning ability, but also emphasis on teamwork, communication skills and teachers' guiding role in the process of teamwork. Reform the traditional teaching method based on teacher-centered; focus on training the students' self-learning ability based on student-centered. Project as a carrier, around certain issues and tasks, teachers gradually guide students for independent learning and deliberate. Teachers play the roles of inspiration, guidance, answer and assessment in the teaching process. The students are no longer passive recipients of knowledge, but active inquiries of knowledge.

Reform curriculum assessment methods. This course will break through the traditional curriculum assessment methods, use the combination of process assessment and target assessment, focus on the assessment of project process and project results. Through using the CDIO assessment standards, comprehensively assess the ability of web project development, innovation and the team cooperation [2]. Therefore, based on different learning effects this course will adopt different assessment methods of usually performance, project practice, project oral defense and final written test. By building a well-established evaluation system, enhance the credibility of the final evaluation results, and truly reflect the student's ability of practical engineering [3].

\section{The Implementation Plan of Curriculum Reform}

The curriculum teaching content is based on the actual needs of enterprises, closely linked with the industries and enterprises. Through analyzing the ability and quality of the web project development engineers, using CDIO engineering teaching method, combined with the training objectives of the course, re-design the content of teaching, and legitimately combine classroom instruction, curricular practices with extracurricular practice.

Curriculum teaching content centers on a complete university graduation work management system. Around the system development process, teach all kinds of knowledge and skill involved in development process of the whole web project, including the web project establishment, demand research, system database design, system interface design, system implementation, testing and deployment, etc. In the process of project development, by issued the commitments let the students to understand their own tasks. Each task consists of task assignment, task implementation, task assessment and complementary explain. Project development process and task decomposition are shown in Fig.1.

Students in extracurricular practice require in-depth market research, complete the project establishment, make detail development plan for project control. For each key project development period, project review must be conducted. After project review is passed, students can start next step of project development. Otherwise students must rework and review again, until the project review is passed.

In the teaching process of this course, adopt small-class teaching mode under 40 people. Reform traditional teaching method; use many kinds of effective teaching methods such as project teaching method, group teaching method, interactive teaching method and so on. Under teacher's guidance by centering on project tasks, using the methods such as personality test, group discussion, students' speech, guide students to actively participate, independently think, and cultivate the interest and innovation ability of actively studying problems. Students gradually shifted from "passive learning" to "active learning" [4].

In the teaching process of web project development course, three kinds of teaching methods are used:

- Project teaching method. In order to improve the students' comprehensive ability to use knowledge, in the teaching process project teaching method is used, teachers and students together implement a complete web project. Issued in the form of the task, students clear learning objective. Combine the learning process and project tasks. At the same time, in the process of practicing project, students are required to learn knowledge and train skills. 
- Group teaching method. The main content of the first lesson is to do a good job in project group. The project group is controlled in 3 to 5 people, with a project leader. Each student needs to complete a detailed personality test of engineering staff, which clears the type of the engineering staff, work and learning habits. Students are grouped according to the test results, try to obtain the highest team cooperation efficiency and improve teaching effects.

- Interactive teaching method. In the process of classroom teaching, teachers' demonstration and project teams' discussion, students' question and teachers' answer form the benign interaction. Let the students in "teaching" and "learning" process truly grasp the method of web project development and have certain project development ability. At each stage of the project review process, each team must make courseware which includes the project design and implementation in the stage. In the classroom each team must explain and discuss with other project teams. Finally, teachers are responsible for review and summarize the design of each project team. After completion of project, the project team must modify the design content itself according to the assessment results. Through this project interactive review, students can strengthen quality consciousness, learn from each other.

This course will break through the traditional examination methods, combine process assessment and objective assessment, pay attention to assess project process and project results. Pay attention to the diversification of assessment. The main content and the weight of course assessment methods are seen in Table I.

The course assessment methods are divided into usual assessment and final assessment. The usual assessment is composed of usual performance and project practice. The final assessment is composed of project oral defense and final exam. More scientific assessment standards are established in each assessment to avoid assessment arbitrariness. Therefore, this curriculum assessment not only can assess students' mastery of the course content, but also can synthetically assess students' originality, exploration and application of knowledge [5].

\section{The Teaching Effects in the Course}

Since the course was combined with CDIO engineering education methods to develop the project teaching, good teaching effects were achieved in the following four aspects.

- Practical engineering ability of students has been greatly improved. By using the CDIO engineering education methods, organize teaching content around the development process of college graduation work management system. Through the form of task driving, students are familiar with software project development process, development technique, programming specification and writing norms of various project documents. Through learning this course, students have the development ability of the actual web projects.

- The ability to analyze and solve problems is further improved. Mainly centering on the tasks in developing college graduation work management system, in the process of developing the system students seek solutions with the problems and tasks by reading, searching and studying all kinds of learning resources, improve their learning efficiency, and enhance their ability of analyzing and solving problems.

- Students' team cooperation and communication ability have been greatly improved. In the teaching process team cooperation mode was taken. In the project implementation process, team members should be in-depth market research, discuss, and finally determined the project development program. After the project was completed, project teams made project summary, shared the experience in project development, learned from each other, and then improved the team cooperation and communication ability.

The students' ability of technology and employment competitiveness is fully improved. Through learning this course, students can develop various types of Web projects. Nearly 2 years, students took part in all kinds of undergraduate science and technology activities associated with the web projects, obtained two Zhejiang Undergraduate Scientific and Technological Innovation Projects, one Zhejiang the second prize of Challenge Cup, two undergraduate software copyright registrations, improved the students' employment ability and quality, which lay a solid foundation 
for future development of students.

\section{Acknowledgement}

This work was supported by teaching reform project of higher vocational education research in Zhejiang Institute of Communications which is named classroom teaching reform and practice of the website design course of medium-sized enterprises.

\section{References}

[1] Edward F. Crawley, Rethinking Engineering Education:the CDIO Approach[M], Beijing: Higher Education Press, 2009.

[2] ZHA Jianzhong, HE Yongshan, Three Major Strategies of the Chinese Engineering Education Reform[M], Beijing: Beijing Institute of Technology Press, 2009.

[3] ZHA Jianzhong, HE Yongshan, Reform of University Teaching Exam and Innovative Personnel Training[J], Journal of Education and Vocational, 2011(32)33-34.

[4] FANG Zhenyu, Approaches of Cultivating Innovative Software Engineering Talents in Higher Educational Institutions[J], Journal of Zhejiang Normal University(Social Sciences), 2012(37) 89-93.

[5] Lin Ling, Discussion of Team and Project Driving Teaching Models in Software Engineering[J], Journal of Fujian Normal University( Natural Science Edition), 2011(27)14-17.

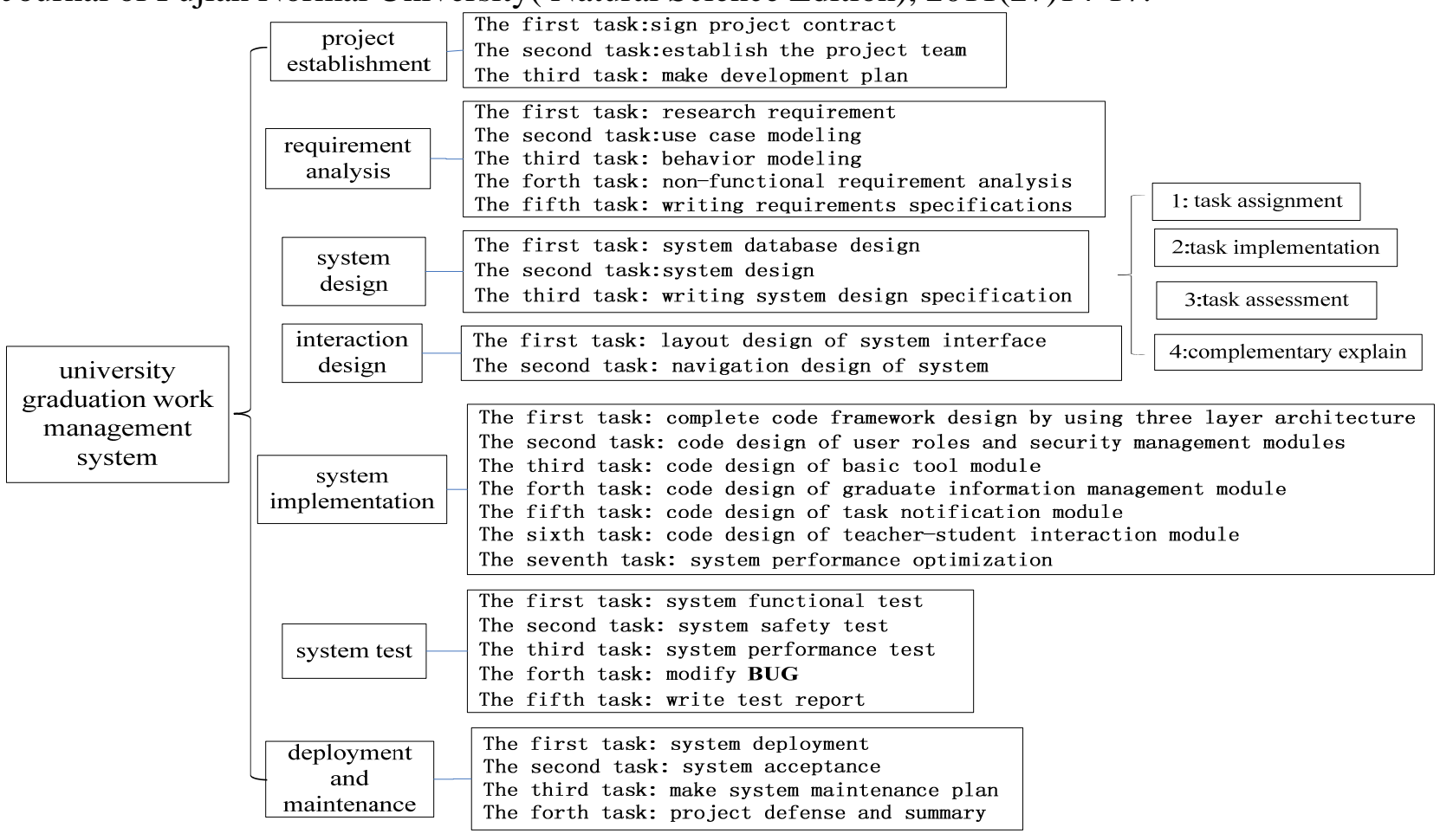

Fig.1. Web project development process and task decomposition

Table I. the main content and the weight of course assessment methods

\begin{tabular}{|c|c|c|c|c|}
\hline Time & Method & Proportion & & Standard \\
\hline \multirow{6}{*}{ Usual } & Usual performance & $20 \%$ & Assess according & the usual attendance, work performance etc. \\
\hline & \multirow{5}{*}{ Project practice } & \multirow{5}{*}{$30 \%$} & Score & Score standards \\
\hline & & & $\begin{array}{l}\text { Excellent } \\
(90 \sim 100)\end{array}$ & $\begin{array}{l}\text { All tasks are successfully completed, the web system } \\
\text { can be normally operated }\end{array}$ \\
\hline & & & Good $(80 \sim 89)$ & $\begin{array}{l}\text { Basic tasks are completed, the web project has some } \\
\text { defects }\end{array}$ \\
\hline & & & Pass $(60 \sim 79)$ & $\begin{array}{l}\text { Finish part tasks(more than } 60 \% \text { ), need help to } \\
\text { basically complete }\end{array}$ \\
\hline & & & $\begin{array}{l}\text { Fail } \\
(<60)\end{array}$ & $\begin{array}{l}\text { Most tasks were unfinished (more than } 40 \% \text { ), web } \\
\text { project structure is a mess. }\end{array}$ \\
\hline \multirow[b]{2}{*}{ Final } & Project defense & $10 \%$ & \multicolumn{2}{|c|}{ Assess by defense, individual project summary. } \\
\hline & Final exam & $40 \%$ & \multicolumn{2}{|c|}{ Assess by the final score. } \\
\hline
\end{tabular}

